\title{
Research on the Experiential Teaching of Scientific Research Course Based on the Cultivation of Innovation and Entrepreneurship
}

\author{
Chunhong Zhang and Yuying Liu
}

Shenyang Aerospace University Shenyang 110136

\begin{abstract}
This paper discusses the important role of university library in innovation and entrepreneurship education, and puts forward the generalist status of literature retrieval course. Use the scientific research experiential teaching method in the text examinations, literature retrieval course. So that students improve the sense of innovation in the scientific research environment and understand the scientific research process. Increase students' practical ability training and innovate thinking training, to create high-quality talents with innovative and entrepreneurial abilities.
\end{abstract}

Keyword: Innovation and entrepreneurship; Literature retrieval course; Scientific research experience; Teaching mode

\section{基于创新创业能力培养的文检课科研体验式教学 \\ 研究}

张春红，刘玉英

(沈阳航空航天大学 沈阳 110136)

文摘: 本文通过论述高校图书馆在创新创业教育中的重要作用, 从而提出发挥文检课的通识课地位, 在文检课中采用科 研体验式教学方法, 让学生在科研体验环境中提高创新意识, 了解科研过程。加大学生的动手能力培养, 创新思维训练, 打 造具备创新创业能力的高素质人才。

关键词: 创新创业; 文检课; 科研体验式; 教学模式

引言:

“大学生创新创业训练计划” 是教育部为培养学生创新意识, 提高学生实践创新能力, 搭建学生创业 平台, 拓宽学生就业渠道而推出深化教学改革的重要举措, 对促进我国培养创新型人才方面具有极其重要 的意义。高校文检课开展大学生创新创业能力培养, 在课程过程中进行创新创业专项训练, 对学生及课程 发展而言, 都具有重要的现实意义。

\section{1. 高校图书馆在创新创业教育中的地位与作用}

\section{1 进行素质教育的重要场所}

当今社会，科技进步日新月异，国际竞争日趋激烈。各国之间的竞争，说到底，就是人才的竞争，是 民族创新能力的竞争。教育是培养科技人才和增强民族创新能力的基础 ${ }^{[2,3,4]}$ 。因此, 我们要源源不断地培 养和造就大批合格的社会主义事业的建设者, 不断造就大批具有主动创新能力的高素质人才, 不断提高整 个中华民族的思想道德素质和科学文化素质。这些素质的养成要求现行的教育空间要扩大, 教育质量要拓 宽, 要从传统 “应试教育” 单一的课堂教育模式向由课堂教育、图书馆教育和社会实践教育三方面相结合 的素质教育转化。而图书馆教育的表现形式既有有形的, 也有无形的; 既有物质的, 也有精神的, 高校图 书馆在素质教育中具有得天独厚的功能与作用。

\section{2 培养学生终生学习能力}

以教育为基础, 实现劳动者知识化和学习终身化是现代信息社会发展的必然趋势, 也是新时期创新教 
育的重要内容。为了跟上时代发展的步伐和知识更新不断加快的进程, 劳动者终身学习将成为必然发展趋 势。图书馆作为储存丰富知识信息的宝库, 它不再是传统意义上的图书馆, 它不仅拥有丰富的文献信息资 源, 还拥有先进的技术手段、完善的服务设施、优雅的学习环境, 同时还拥有一支高素质的知识信息检索 和研究专家队伍, 他们可以帮助和指导读者解决各种疑难问题, 使读者接受教育、获取新知识的过程更加 畅通。此外, 逐步走向社会化的高校图书馆, 除了教师、科研人员和学生可以利用外, 各种类型的读者都 可以利用图书馆获取自己所需的知识信息, 从事自己的学习和研究。因此, 要想进行创新和科学研究就得 去利用图书馆, 学会挑选和利用对自己有用的信息, 这是创新的一个最直接的方法。由此可见, 高校图书 馆是实施终生教育的最佳场所。

\section{3 开展通才教育的最佳机构}

通才教育是指建立在拓宽基础知识前提下的专业教育。一些实行通才教育比较好的国家, 都把图书馆 作为大学教学和科研工作的知识宝库, 因为大学图书馆能在崇尚学习的知识经济的环境下, 充当读者技能 培养的重要教育机构, 训练和培养他们的获取知识能力、主动学习能力、独立研究能力等。实际上, 大学 图书馆采用比较主动、灵活多样的教育方式, 通过书评、书展、讲座、交流等活动方式, 采取一身示教的 方式, 注意培养学生的独立性、创造性和开拓性, 使高等教育逐渐从专才教育向通才教育转变, 使高校图 书馆真正扮演着通才教育的重要基地的角色。

\section{2. 创新创业能力培养的重要性}

1997 年, “清华大学创业计划大赛” 正式拉开了我国创业教育的帷幕。2002 年, 教育部确定 9 所高校 为创业教育试点单位后, 大学生创业教育在我国高校全面铺开 ${ }^{[5]}$ 。但是, 从整体上看, 我国创业教育尚处 于起步摸索阶段，在热闹的现状背后，创业教育在政策上的若干缺失值得反思。与国外中小企业的兴起和 发展推动创业教育的繁荣不同, 中国创业教育最主要的原动力来自于社会发展函须解决的就业问题。当前, 我国创业教育目标设定的功利性、创业教育理解的片面性、创业教育支撑体系的局限性以及创业教育课程 体系的单一性, 已不能适应知识经济对创新创业型人才培养的更高要求。针对国内创业教育中的问题, 借 鉴国外特别是美国的成功经验，我国应从提高整个国民素质的高度出发，把创新创业型人才培养与研究型 人才、应用型人才的培养放在同等重要的地位, 鼓励和倡导各类大学开展各种形式的创新创业教育, 并把 创业家和各类社会创业资源引入高校, 密切企业、社会和学校的联系, 使创新创业型人才培养逐步成为我 国高等教育人才培养体系的一个重要组成部分。

\section{3. 文检课融入创新创业教育的方案}

在文检课中融入创新创业教育, 采用科研体验式教学模式, 结合学校的 “大创项目”, 让学生在文检 课中体验科研的过程, 文献检索、整理、分析, 项目题目拟定, 寻找科研方法, 创新研究内容, 给予大学 生专利申报的分析。通过这样的过程, 提高学生的创新意识, 打造具有创业能力的高等人才 ${ }^{[1]}$ 。

\section{1 课题来源与拟定}

课题任务的拟定将结合文检课的课程特点以及学生的学习程度而定。由于大学生创新创业训练周期通 常为一年, 而文检课教学课时也就一个学期, 学生在学习文检课前对专业知识还涉猎较浅, 研究较深入的 创新项目在时间及知识能力上还难以做到。通常不建议学生做需求投入大量时间精力研究的专深的创新, 学生可以结合解决平时专业课学习中遇到的问题, 也可以结合个人兴趣爱好、身边的现实问题及社会关注 
热点尝试一些有价值的探索。大学生创新创业训练计划包括创新训练项目、创业训练项目和创业实践项目 三种类型。文检课的学习重在培养学生获取信息、分析评价、综合利用信息的能力。实践中, 文检课研究 项目主要以创新训练项目为主，创业训练项目为辅。

\section{2 教学设计}

在教学设计上，根据创新创业项目研究的阶段性要求，结合馆藏及网络资源，综合运用各类信息资源， 将信息素养各培养目标融入到项目研究体验中。课程总体上可分为科研准备与选题、立项申请、项目实施、 项目总结等四个循序渐进的阶段，每个阶段根据项目进程安排相应的讲授内容。

\section{3 教学方法}

基于大学生创新创业训练的文检课教学模式实施 “项目驱动式” 探究性教学策略, 以体验项目研究为 主线贯穿课程始终, 教学上以学生为主体, 以教师为主导。教学内容灵活多样, 不同于以往文检课的系统 知识教学按教学大纲讲授相对固定的单元内容。加强课程教学中实践性任务及学习交流活动。以学生为 主体, 学生三五人一组, 通过资料检索、社会调研、交流讨论、论文撰写、成果汇报等活动, 切实参与 项目创新研究。在项目研究中, 鼓励学生自由发表意见和质疑, 培养学生的主体意识和创新精神。教师 通过合理的教学设计引导学生按照项目的阶段进程完成任务, 并在项目研究的全过程给予指导, 包括选题 的合理性，项目实施的目的、意义、内容、方案等申报内容填写，资料搜集与调研方法、商业计划书的编 写、成果总结与发表等。教学上采用基于资源的教学法及基于案例的教学法。教学内容融入图书馆馆藏 资源及信息服务的介绍，开展专业资源及项目资源调研。此外，结合各级各类大学生创新创业项目及图书 馆科研课题开展实例教学, 使学生体验到真实的科研活动情景。

\section{4 教学评价}

一种教学模式的好坏, 实施过程固然重要, 但是所获得的教学结果及教学评价同样非常重要。将创新 创业教育引入文检课教学中, 让学生体验科研环境, 评价的方法自然不能像传统教学的方式, 考试、写论 文等。而是要综合评价学生在整个过程的把控能力。在项目实施过程中, 注意观察学生的资料搜集能力, 整理能力, 在最终结果行程阶段, 重点考察学生的成果分析、汇报能力。从而学生的综合素质得以提高, 也形成了科研体验式教学模式的独特教学评价。

\section{4. 总结}

一个完善的教学体系能够带动学生更好的融入课程环节。创新创业大背景下, 高校教育更是培养出色 人才的摇篮, 紧跟国家政策, 尽快建立完善的创新创业培养计划, 扩大投入, 增加创新创业教学资源, 为 培养出具有创新精神、创业能力的大学生而不断努力。

\section{参考文献:}

[1] 杜安平. 基于大学生创新创业训练的文检课教学模式研究 [J]. 图书馆研究, 2016 (2)：111-114

[2] 任玉梅，吴秀玲. 基于创业教育视阈下高校图书馆优势服务建设 [J]. 晋图学刊，2011(2)：54-57

[3] 于洪升. 试论高校图书馆在创新教育中的作用及其对策[J].中国成人教育，2019（15)：43-44

[4] 张天华, 张天华. 高校创新创业教育的教学资源开发研究 [J]. 辽宁工业大学学报 (社会科学版), 2015, 17 (4):75-78

[5] 李宏宇，张宝玉，王晓文. 高校图书馆支持大学生科技创新的研究与实践[J]. 晋图学刊. 2012（3）:50-52

\section{Reference:}

[1] Du Anping Research on Teaching Mode of Document Retrieval Course Based on College 
Students' Innovative Entrepreneurship Training [J]. Library Studies, 2016 (2): 111-114

[2] Hou Yumei, Wu Xiuling Construction of University Library's Advantage Service Based on Entrepreneurship Education [J]. Shanxi Library Journal, 2011 (2): 54-57

[3] Yu Hongsheng on the Function and Countermeasures of University Library in Innovative Education [J]. China Adult Education, 2019 (15): 43-44

[4] Zhang Tianhua Research on the Development of Teaching Resources for Innovative and Entrepreneurship Education in Colleges and Universities [J]. Journal of Liaoning University of Technology (Social Science Edition), 2015,17 (4): 75-78

[5] Li Hongyu, Zhang Baoyu, Wang Xiaowen Research and Practice of University Library's Supporting Scientific and Technological Innovation of College Students [J]. Shanxi Library Journal.2012(3):50-52 